\title{
OS LIMITES DA ATUAÇÃO DA ADVOCACIA-GERAL DA UNIÃO NA POLÍTICA ESTATAL DE "DESJUDICIALIZAÇÃO"
}

\author{
http://dx.doi.org/10.21527/2176-6622.2021.55.78-88
}

Recebido em: 17/10/2019

Modificações solicitadas em: 20/4/2020

Aceito em: 21/7/2020

Daniel Mota Gutiérrez

Autor correspondente. Centro Universitário Christus - Unichristus. Av. Dom Luís, 911 - Meireles. CEP 60160-230. Fortaleza/CE, Brasil. http://lattes.cnpq.br/3876922135149385. https://orcid.org/0000-0002-8314-1524.dgutierrez@uol.com.br

\section{Natália Ribeiro Machado Vilar}

Centro Universitário Christus - Unichristus. Fortaleza/CE, Brasil.

\section{RESUMO}

No presente artigo foram analisados os principais óbices à participação mais efetiva do Poder Público Federal, por intermédio da Advocacia-Geral da União (AGU), na política de meios adequados de gestão de conflitos vigente no Brasil. A análise foi realizada sob a perspectiva do postulado da desjudicialização e considera o cenário da crise de litigiosidade no âmbito do Poder Judiciário brasileiro. Verificou-se que, apesar da existência no Brasil de uma política pública oficial de solução consensual de conflitos, esta não foi acompanhada do oferecimento de condições estruturais, normativas e técnicas suficientes para o adequado envolvimento da Administração Pública Federal. Conclui-se que, diante desse cenário, revela-se imprescindível, dentre outras medidas, uma regulamentação normativa que viabilize concretamente a política de consensualidade no âmbito da atuação da AGU, de modo a inserir, de forma integral, a Administração Pública Federal no contexto da política estatal de desjudicialização.

Palavras-chave: Meios equivalentes de jurisdição. Consensualidade. Advocacia-Geral da União. Legislação. Desjudicialização.

\section{THE ATTORNEY GENERAL’S OFFICE'S PERFORMANCE LIMITS IN THE STATE POLICY ON “DEJUDICIALIZATION”}

\section{ABSTRACT}

In this article, we analyzed the main obstacles to the most effective participation of Federal Government's, through the Attorney General's Office (AGU), in the policy of alternative dispute resolution (ADR). The analysis was carried out from the perspective of the postulate of dejudicialization and considers the scenario of the litigation crisis within the Brazilian Judiciary. It was found that, despite the existence in Brazil of an official public policy for the consensual solution of conflicts, this was not accompanied by the provision of sufficient structural, normative and technical conditions for the proper involvement of the Federal Public Administration. We conclude that it is necessary, among other measures, the existence of a law that allows the policy of consensuality, within the scope of the AGU's performance, to insert the Federal Public Administration in the context of the state policy of dejudicialization.

Keywords: Alternative dispute resolution (ADR). Consensuality. Union Attorney General. Legislation. Dejudicialization.

\section{SUMÁRIO}

1 Introdução. 2 A crise de litigiosidade e o poder público federal. 3 O postulado da desjudicialização no código de processo civil de 2015 e a política da gestão consensual de conflitos no estado brasileiro. 4 A atuação da advocacia-geral da União ante o postulado da desjudicialização. 5 Considerações finais. 6 Referências. 


\section{INTRODUÇÃO}

O Código de Processo Civil de 2015 adotou expressamente uma política estatal de incentivo à consensualidade, o que foi especialmente destacado, em suas normas fundamentais, na previsão do artigo 3으, §§ 2응 e 3ํㅡ, ao dispor que deverá o Estado promover e estimular a solução consensual de conflitos (BRASIL, 2015a). Apesar disso, o Executivo Federal figura em mais de $50 \%$ dos processos que tramitam no Supremo Tribunal Federal (FALCÃO; CERDEIRA; ARGUELHES, 2011).

Diante desse cenário, buscou-se examinar se o Poder Público Federal, por meio da Advocacia-Geral da União ${ }^{1}$ (AGU), está devidamente estruturado e preparado para efetivar a referida diretriz da consensualidade, tendo em vista alguns entraves enfrentados pelos profissionais desta instituição, para harmonizar as suas atividades com os meios equivalentes ${ }^{2}$ de solução de conflitos.

Para a contextualização da temática analisou-se, primeiramente, a participação do Poder Público Federal no cenário da crise de litigiosidade do Poder Judiciário brasileiro. Na sequência, destacaram-se, em especial, as disposições do CPC/2015 sobre a política da consensualidade no Estado brasileiro. Posteriormente, apontaram-se alguns óbices relativos à atuação da AGU no cenário de busca pela efetivação de meios equivalentes de solução de conflitos.

Por meio do método dedutivo, pautado na análise crítica da doutrina e da legislação sobre a matéria, apontou-se a importância de enfrentamento da problemática apresentada neste trabalho, com o objetivo de promover a política da desjudicialização por intermédio da atuação desenvolvida pelos advogados que compõem a AGU.

\section{A CRISE DE LITIGIOSIDADE E O PODER PÚBLICO FEDERAL}

É possível verificar no Relatório Justiça em Números, publicado em 2019 pelo Conselho Nacional de Justiça (CNJ), que o Brasil atravessa uma reconhecida crise de excesso de litigiosidade. Embora o ano de 2017 tenha sido o primeiro de uma série histórica na qual se constatou um freio no acervo, o qual crescia desde 2009, ainda assim verifica-se que no final do ano de 2018 o Poder Judiciário contava com 78,7 milhões de processos em tramitação (CNJ, 2019, p. 79-81).

Apesar dessa redução, que se deve à diminuição de 861 mil novos processos perante a Justiça do TrabaIho (CNJ, 2019), não houve modificação no panorama do Judiciário, que permanece sendo provocado como o principal instrumento de solução da insatisfação popular, pois "a expectativa de que a Justiça possa funcionar como instância moral não se manifesta somente em pressuposições de cláusulas legais, mas também na permanência de uma certa confiança popular" (MAUS, 2000, p. 190) ou de interesse contrariado dos brasileiros (CARMONA, 1998).

De acordo com Araken de Assis (2006), na sociedade pós-moderna os cidadãos etiquetados ("consumidor", "contribuinte" e outros) assumem a "condição de litigante inveterado e intransigente" (p. 199-200), acentuando-se o comportamento demandista e a síndrome de litigiosidade da sociedade moderna. Constata-se "um colapso do modelo de jurisdição estatal, que não responde de modo eficiente à complexidade social e litigiosa, havendo um descompasso entre procura e oferta de serviço" (REIS; BORGES; SILVA NETO, 2020, p. 41).

\footnotetext{
1 “Nos termos do art. 131 da Constituição, 'a Advocacia-Geral da União (AGU) é a instituição que, diretamente ou através de órgão vinculado, representa a União, judicial e extrajudicialmente, cabendo-lhe, nos termos da lei complementar que dispuser sobre sua organização e funcionamento, as atividades de consultoria e assessoramento jurídico do Poder Executivo'".

2 Utiliza-se, para as finalidades deste trabalho, as expressões "meios equivalentes" ou "meios adequados" no mesmo sentido.
} 


\section{Debate}

Por outro lado, o problema também pode ser analisado pela perspectiva do modo de solução dos litígios. Nesse sentido, verificam-se entraves instrumentais relativos aos mecanismos de gestão ou resolução de conflitos, agravados pelos escassos meios materiais que são finitos e exigem demasiadamente do orçamento público para manutenção do funcionamento da Justiça. ${ }^{3}$

A crise de litigiosidade não tem sido ignorada. As normas processuais têm se tornado mais sofisticadas para atender às causas do excesso de litigiosidade, como o uso de precedentes, a barreira de recursos repetitivos, a compactação de procedimentos, as cognições parciais e outros, mas "[...] tais filtros, barreiras ou elementos de contenção vêm sendo positivados sem uma indagação mais profunda [...], e sem uma preocupação maior com a questão de fundo que está à base do problema [...]: uma cultura demandista ou judiciarista" (MANCUSO, 2015, p. 31).

É importante registrar que o excesso de litigiosidade dificulta a realização do direito constitucional de acesso à justiça, na medida em que o Judiciário não consegue dar solução adequada para a multiplicidade de demandas que ingressam anualmente nas estatísticas forenses.

Como indicado por Mancuso (2015), podem ser muitas as causas geradoras do excesso de litigiosidade, como: a) a cultura demandista; b) a fúria legislativa; c) o binômio judicialização da política-politização do Judiciário; d) o ativismo judicial fomentado pela conduta dos outros poderes; e) a existência de litigantes habituais; f) o gigantismo da máquina judiciária que retroalimenta a demanda; g) a litigiosidade contida e sua recepção pelos Juizados Especiais; e h) a deficiente divulgação de outros meios de solução de conflitos.

Outro aspecto que merece destaque é o dado decorrente de estudo (FALCÃO; CERDEIRA; ARGUELHES, 2011) apoiado pela Fundação Getúlio Vargas (FGV/Direito Rio), que, ao investigar a litigiosidade no âmbito do Supremo Tribunal Federal (STF), concluiu que "o grande cliente do STF Recursal é de natureza pública" (p. 68), complementando que, sozinho, o Executivo Federal representa mais de $50 \%$ de todos os processos tramitando na Suprema Corte.

A análise reflexiva desses dados estatísticos, produzidos anualmente pelo CNJ por meio do Relatório Justiça em Números, e de outros relatórios de tramitação processual, a exemplo do supracitado, elaborada pela FGV, é importante para auxiliar na percepção de "gargalos" de litigiosidade, bem como para orientar medidas de tratamento com vistas a melhorar a referida realidade.

Assim, de acordo com o estudo e o relatório apontados anteriormente, a constatação de que o Sistema de Justiça não funciona adequadamente e que o Poder Público Federal é responsável por mais de 50\% da demanda judicial dos recursos que tramitam no STF, exige uma reflexão de como dar efetividade ao direito constitucional do acesso à justiça.

A diminuição do número de litígios pelo próprio Poder Público, em especial o Executivo Federal, possibilitaria um melhor resultado da própria prestação jurisdicional, uma maior eficiência do Estado e um ganho de harmonia social.

Um método que pode ser utilizado para propiciar um tratamento mais adequado dos conflitos, com a consequente diminuição de processos judiciais, diz respeito ao incentivo e à sedimentação de meios equivalentes de jurisdição.

Na Inglaterra, como aponta Neil Andrews (2012), "os protocolos pré-litígios disciplinam o processo da negociação, que visa à realização de acordo antes do começo do processo", havendo, assim, uma verdadeira e eficaz política de "apoio oficial para o acordo" (p. 348-350).

Nos Estados Unidos (EUA), Owen Fiss (2004) relata o interesse nas chamadas "práticas amigáveis" como estratégia para prevenção de conflitos, em momento anterior à propositura da ação judicial. Aponta, ainda, a existência de uma "comum inclinação do currículo jurídico com vistas a preparar os estudantes para o com-

\footnotetext{
Jorge Neto (2016) informa que "para processar e julgar de 2.000 a 5.000 processos em um tempo hábil, o juiz precisa ser auxiliado por um corpo de servidores preparado [...] O problema é que, em muitas unidades jurisdicionais, em muitas varas, o juiz tem apenas dois ou três auxiliares, normalmente cedidos das prefeituras e sem a adequada capacitação técnica [...] 0 resultado é que os juízes trabalham à exaustão, mas os processos não andam. Os juízes só conseguem dar conta dos pedidos urgentes [...] Além de servidores qualificados, muitas vezes faltam [...] instalações adequadas, computadores modernos e até acesso à internet" (JORGE NETO, Nagibe de Melo. Abrindo a caixa preta: por que a Justiça não funciona no Brasil? 1. ed. Salvador: Editora Juspodvm, 2016. p. 84).
} 
bate jurídico", bem como a sugestão para que "[...] as Faculdades de Direito orientassem seus alunos para práticas amigáveis da conciliação e do acordo" (FISS, 2004, p. 121). Percebe-se, assim, o propósito explícito destinado a incutir na sociedade norte-americana uma cultura de promoção da consensualidade.

Marcelo Veiga Franco (2015) afirma que nos EUA aproximadamente 80\% das controvérsias são resolvidas pelos sistemas alternativos de solução de conflitos, como mediação e arbitragem (p. 256).

No Brasil, é possível verificar que as disposições trazidas pelo Código de Processo Civil de 2015, em especial no artigo 3o, bem como pela Resolução no 125/2010, do Conselho Nacional de Justiça, pretendem a introdução de uma política nacional de estímulo à consensualidade e ao tratamento adequado de conflitos.

No cenário brasileiro, entretanto, ainda há necessidade de desenvolvimento e aprimoramento da cultura da consensualidade. Essa percepção foi incorporada na Resolução no 5/2018 do Ministério da Educação, ao incluir, nas Diretrizes Curriculares do Curso de Direito de 2018, a importância do aprendizado a respeito dos meios de composição consensual de conflitos (artigo 3으).

Não se pode ignorar, portanto, que há uma tentativa de rompimento da tradição processual demandista por meio da adoção de uma política pública oficial de alternativas não adjudicatórias de solução de conflitos, a qual envolve a Administração Pública e os seus usuários.

\section{O POSTULADO DA DESJUDICIALIZAÇÃO NO CÓDIGO DE PROCESSO CIVIL DE 2015 E A POLÍTICA DA GESTÃO CONSENSUAL DE CONFLITOS NO ESTADO BRASILEIRO}

Como apontado no tópico anterior deste trabalho, é possível verificar, no Brasil, a adoção de uma política de promoção aos meios equivalentes de jurisdição, que pode ser verificada, especialmente, por intermédio de três normas emanadas pelos três Poderes - o Executivo, o Legislativo e o Judiciário.

O Código de Processo Civil de 2015 (CPC/2015), decretado pelo Congresso Nacional (Poder Legislativo), adotou expressamente a política de incentivo à consensualidade, especialmente na previsão do artigo 3으, §§ 2 e 3으, que compõe seu corpo de normas fundamentais ao dispor que a promoção e o estímulo à solução consensual de conflitos é dever do Estado (BRASIL, 2015a).

No âmbito do Poder Judiciário, a Resolução no 125/2010, do Conselho Nacional de Justiça (CNJ), "dispôs e regulamentou, pela primeira vez, a mediação e conciliação em âmbito brasileiro, instituindo a Política Judiciária Nacional de Tratamento adequado dos Conflitos de Interesses no âmbito do Judiciário" (GRIEBLER; SERRER, 2020, p. 171).

O Poder Executivo também encampou a referida política pública por meio da Resolução no 5/2018, do Ministério da Educação, ao instituir as Diretrizes Curriculares do Curso de Direito de 2018, prevendo a importância de "assegurar, no perfil do graduando, [...] o domínio das formas consensuais de composição de conflitos" (artigo 3ㅇ) (BRASIL, 2018).

Para o presente trabalho interessa, em particular, a política instituída no modelo inaugurado pelo $\mathrm{CPC} / 2015$, que contemplou algumas cláusulas gerais, como a referida "promoção da solução consensual dos conflitos" (artigo 3ㅇ, § 2ㅇ) , além do "dever de cooperação" (artigo 6ㅇ) e a "possibilidade de negociação processual" (artigo 190).

Sob esse enfoque, denomina-se como "postulado da desjudicialização" esse conjunto de normas previstas no CPC/2015, cuja tendência é estimular um modelo multiportas, agregando os meios alternativos à solução jurisdicional tradicional, buscando-se "a adoção de uma solução integrada dos litígios, como corolário da garantia constitucional do livre acesso do inc. XXXV do art. 5 da CR/1988" (THEODORO JÚNIOR, 2015, p. 213).

Como já referido, destaca-se, do § 2ํㅡ, artigo 3ำ, do CPC, um dever estatal de "promoção da solução consensual dos conflitos", e, do $\S 3$ o, do mesmo artigo, um dever de estímulo aos métodos que fortaleçam essa espécie de resolução pelos juízes, advogados, defensores públicos e membros do Ministério Público, inclusive no curso do processo judicial (BRASIL, 2015a).

Percebe-se, nesse aspecto, que foi utilizada a expressão "inclusive no curso do processo judicial", ficando, assim, expressamente registrado que o sistema de Justiça e o dever estatal de promoção e estímulo aos métodos de solução consensual de conflitos não se limitam ao âmbito do Poder Judiciário. 


\section{Debate}

Por sua vez, o artigo 60 do CPC/2015 estabelece que "todos os sujeitos do processo devem cooperar entre si para que se obtenha, em tempo razoável, decisão de mérito justa e efetiva". Relativamente aos Poderes, deveres e responsabilidades, o artigo 139, inciso $V$, do mesmo diploma legal, determina que incumbe ao juiz "promover, a qualquer tempo, a autocomposição, preferencialmente com auxílio de conciliadores e mediadores judiciais".

Nessa linha, é de se destacar ainda o artigo 174, do mesmo CPC, que estabelece a necessidade de criação, pelos entes públicos, de "câmaras de mediação e conciliação, com atribuições relacionadas à solução consensual de conflitos no âmbito administrativo", para o fim de "dirimir conflitos envolvendo órgãos e entidades da administração pública", "avaliar a admissibilidade dos pedidos de resolução de conflitos, por meio de conciliação, no âmbito da administração pública", e "promover, quando couber, a celebração de termo de ajustamento de conduta".

Não resta dúvida, portanto, que o próprio Direito Processual Civil passa a receber os influxos da lógica da "desjudicialização", que foi eleita como política nacional de gestão ou solução de conflitos, não se tratando somente de um dever do Estado-juiz, mas também dos demais Poderes e de seus órgãos.

\section{A ATUAÇÃO DA ADVOCACIA-GERAL DA UNIÃO ANTE O POSTULADO DA DESJUDICIALIZAÇÃO}

Como já consignado, extrai-se do sistema jurídico brasileiro, especialmente do CPC/2015, a orientação de uma política nacional de gestão ou solução consensual de conflitos, inclusive com a promoção do postulado da "desjudicialização". É de se destacar, ainda, nesse contexto, a Lei no 13.140/2015, que "dispõe sobre a mediação entre particulares como meio de solução de controvérsias e sobre a autocomposição de conflitos no âmbito da administração pública" (BRASIL, 2015b).

Como será exposto adiante, em relação ao Poder Público, contudo, ainda não se observou expressivos avanços decorrentes da aludida política nacional, mesmo tendo sido o próprio Estado o maior incentivador da cultura da "desjudicialização".

Quando as partes envolvidas são particulares, é menos problemática, de uma maneira geral, a efetivação dos meios equivalentes de jurisdição, tendo em vista uma maior flexibilidade quanto à disponibilidade dos interesses individuais patrimoniais. Diferentemente ocorre, todavia, quando a Fazenda Pública integra a relação jurídico-processual.

Apesar disso, primeiramente é de se enfatizar que indisponibilidade não pode ser confundida com intransigibilidade, o que seria uma interpretação incompatível com o atual sistema jurídico brasileiro. Embora não seja objeto do presente trabalho, a análise pormenorizada de quais espécies de demandas podem ser incluídas em eventual rol de causas transacionáveis, é de se registrar que não é possível extrair uma suposta intransigibilidade ou indisponibilidade processual da tradicional lição oriunda do direito administrativo sobre indisponibilidade do interesse público.

Aliás, a Lei no 13.129/2015, que alterou a Lei de Arbitragem (Lei no 9.307/1996), acrescentou a possibilidade de a Administração Pública (direta e indireta) utilizar a arbitragem para dirimir conflitos relativos a direitos patrimoniais disponíveis.

Ademais, diante do contorno que se tem dado ao direito constitucional de acesso à justiça, inspirado pela ideia da desjudicialização dos conflitos (MANCUSO, 2015), o processo judicial é apenas uma das importantes técnicas para se atingir o interesse público de tratamento adequado de um conflito, devendo cada instrumento de acesso à justiça ser avaliado no contexto das circunstâncias do caso concreto.

Considerando-se, ainda, a política estatal que promove o postulado da desjudicialização, a evidente litigiosidade que envolve o Poder Público, bem como a superação da ideia de uma absoluta e genérica indisponibilidade do interesse público, não parece coerente, com a sistemática jurídica atual, defender que a Administração Pública e a Advocacia Pública fiquem à margem da atual interpretação e perspectiva relacionada ao princípio do acesso à justiça.

Vale lembrar que, embora a Advocacia Pública tradicionalmente atue, com maior ênfase, na atividade contenciosa e defensiva, ostenta, inexoravelmente, a condição constitucional de função essencial à justiça, inclusive com competência de controle interno de juridicidade do ato administrativo (MADUREIRA, 2016). 
Na prática, contudo, são bastante limitadas as possibilidades de negociação ou utilização dos meios consensuais conferidos aos membros da Advocacia Pública enquanto representantes da União.

Com efeito, a possibilidade de atuação da AGU ainda resume-se, basicamente, às Câmaras de Conciliação e Arbitragem da Administração Federal (CCAF) ${ }^{4}$ cuja lei reguladora é anterior à vigência do atual CPC, além de atividades decorrentes de autorizações pontuais para celebração de acordos (limitadas por baixas alçadas e normalmente condicionadas à permissão de autoridades centrais e geograficamente distantes dos conflitos locais), ou, mesmo, em raras hipóteses, condicionadas a temas já definidos por jurisprudência sedimentada de cortes superiores ou sumuladas administrativamente, conforme a Lei Orgânica da AGU (Lei Complementar no 73/1993).

A realidade mostra-se tão desfavorável à promoção da solução consensual de conflitos por meio da AGU que, com o advento do CPC de 2015, a Procuradoria da União no Estado do Ceará encaminhou o Ofício no 00019/2016/GAB/PUCE/PGU/AGU-MEFA, de 24 de março de 2016, ${ }^{5}$ informando ao diretor do Foro da Seção Judiciária do Estado do Ceará a dificuldade ou mesmo impossibilidade de atuação da referida procuradoria em razão da inexistência ou limitação de "margem" para realização de acordos ou transações em processos judiciais.

O referido ofício, redigido logo após a vigência do então "novo" Código de Processo Civil (CPC), buscou alertar acerca dos obstáculos enfrentados pelos advogados da União na participação da audiência de conciliação ou mediação inaugurada como etapa obrigatória pelo artigo 334, caput, do referido novo diploma.

Embora ressaltando a importância da sedimentação da cultura conciliatória e do sistema "multiportas" de solução dos litígios, foram apresentados, no referido ofício, os sérios obstáculos normativos enfrentados, tendo em vista que a Lei $n$ o 13.140/2015, ao alterar a Lei no 9.469/1997, retirou a eficácia de todo o marco regulamentador para os acordos ou transações no âmbito da Procuradoria-Geral da União. Assim, ante a inexistência de normatização expressa, expedida pelas autoridades competentes, concluiu-se que praticamente não existe margem para as procuradorias judiciais da União realizarem acordos ou transações em processos judiciais.

Diante da referida impossibilidade legal, solicitou-se, no mencionado ofício, que fosse aplicada automaticamente a regra de exceção contida no inciso II do parágrafo 4o do artigo 334 do $\mathrm{CPC}^{6}{ }^{6}$ de modo a não ser determinada a realização de audiência de conciliação ou mediação.

Vê-se, portanto, que, embora não se ignore toda a sistemática trazida pelo CPC/2015, o próprio Estado brasileiro não se estruturou adequadamente para atuar conforme a política nacional por ele mesmo instituída, no caso, em relação às suas procuradorias estaduais de representação da União.

Resta, assim, extremamente limitada a atuação das Procuradorias da União nos Estados quanto à possibilidade de realização de acordos judiciais, sendo, como dito, sempre condicionadas a temas já definidos por jurisprudência sedimentada ou súmulas administrativas, às baixas alçadas e à permissão de autoridade central, geograficamente distante dos conflitos locais.

\footnotetext{
${ }^{4}$ A Câmara de Conciliação e Arbitragem da Administração Federal (CCAF) foi instituída pelo Ato Regimental no 5/2007 (alterado pelo Ato Regimental $n^{\circ}$ 2/2009). Sua estrutura está definida pelo Decreto $n$ - 7.392/2010 (alterado pelo Decreto $n$ o 7.526/2011) que estabelece: "Art. 18. À Câmara de Conciliação e Arbitragem da Administração Federal compete: I - avaliar a admissibilidade dos pedidos de resolução de conflitos, por meio de conciliação, no âmbito da Advocacia-Geral da União [...]; III - dirimir, por meio de conciliação, as controvérsias entre órgãos e entidades da Administração Pública Federal, bem como entre esses e a Administração Pública dos Estados, do Distrito Federal, e dos Municípios; IV - buscar a solução de conflitos judicializados, nos casos remetidos pelos Ministros dos Tribunais Superiores e demais membros do Judiciário, ou por proposta dos órgãos de direção superior que atuam no contencioso judicial; V - promover, quando couber, a celebração de Termo de Ajustamento de Conduta nos casos submetidos a procedimento conciliatório; VI - propor, quando couber, ao Consultor-Geral da União o arbitramento das controvérsias não solucionadas por conciliação; e VII - orientar e supervisionar as atividades conciliatórias no âmbito das Consultorias Jurídicas nos Estados. Informação disponível em: https://www.agu.gov.br/page/ content/detail/id_conteudo/170561. Acesso em: 13 jun. 2019. Para mais informações, conferir a "Cartilha CCAF", disponível em: https:// www.agu.gov.br/page/content/detail/id_conteudo/217576. Acesso em: 13 jun. 2019.

Trata-se de comunicação da referida Procuradoria à Justiça Federal do Ceará, razão pela qual não é um documento acessível a todos, por meio de publicação oficial. Registre-se, contudo, que tal ofício é utilizado de forma reiterada, sendo mencionado nos despachos de citação da "União Federal" no âmbito da Justiça Federal do Ceará, desde o início da vigência do Código de Processo Civil de 2015 até junho de 2020.

6 O CPC/2015 estabelece o seguinte: "Art. 334. Se a petição inicial preencher os requisitos essenciais e não for o caso de improcedência liminar do pedido, o juiz designará audiência de conciliação ou de mediação com antecedência mínima de 30 (trinta) dias, devendo ser citado o réu com pelo menos 20 (vinte) dias de antecedência [...] § 4으 A audiência não será realizada: I - se ambas as partes manifestarem, expressamente, desinteresse na composição consensual; II - quando não se admitir a autocomposição".
} 
Como já aventado, os procuradores dependem de autorização administrativa expressa para realização de acordos nos termos da legislação específica (artigo 2o, caput, da Lei no 9.469/1997, com redação dada pela Lei no 13.140/2015), ${ }^{7}$ de modo que, nas causas em que a União for parte, o Procurador-Geral da União (autoridade central lotada em Brasília) poderá autorizar a realização de acordos para prevenir ou terminar, judicial ou extrajudicialmente, litígio que envolver valores inferiores aos fixados em regulamento.

Vale pontuar que o referido regulamento, ainda não editado, deverá estabelecer, também, as hipóteses em que os órgãos de execução receberão delegação para celebrar acordos, bem como a sistemática baseada em valores escalonados de alçada.

Além das mencionadas dificuldades, não se pode ignorar ainda o receio dos advogados públicos de serem responsabilizados e punidos pela não apresentação de defesa contenciosa nos casos concretos, tendo em vista que somente no âmbito dos Juizados Especiais há previsão legal (Lei no 10.259/2001) para a propositura do acordo e, nos demais casos, não existe normatização segura, exaustiva ou mesmo suficiente sobre o tema (FACCI, 2015), o que limita (e muitas vezes, impede) a realização da política nacional de consensualidade no âmbito da Justiça Federal Comum.

Não é difícil perceber o impacto negativo à toda sociedade decorrente da ausência ou insuficiência dos meios e autorizações necessários para que a Advocacia Pública Federal possa atuar também fazendo uso pleno das técnicas equivalentes de jurisdição. Em relação à AGU, é extenso o âmbito de atuação dos advogados que a compõe, tendo em vista as mais variadas ações que tramitam nos órgãos do Poder Judiciário onde atuam, como o Supremo Tribunal Federal, o Superior Tribunal de Justiça, o Superior Tribunal Eleitoral, a Justiça do Trabalho, a Justiça Eleitoral, a Justiça Militar, a Justiça Federal e as Justiças dos Estados e do Distrito Federal. ${ }^{8}$

Para se ter ideia do impacto que isso pode gerar, veja-se, por exemplo, a situação da Justiça Federal, na qual estavam pendentes de julgamento, 9.871 .324 milhões de processos não criminais até o final do ano de 2018 (CNJ, 2019, p. 36). Tendo em vista a referida competência da Justiça Federal, pode-se afirmar que a maioria dessas milhões de ações não criminais pendentes tem como representante judicial os advogados públicos que compõem os quadros da AGU. ${ }^{9}$

A impossibilidade de dar tratamento adequado aos conflitos inseridos na rotina de atuação dos membros da AGU, portanto, reflete em uma vultosa quantidade de demandas. O impacto dessa constatação ganha maior dramaticidade ao se destacar as relevantes questões envolvidas nas ações da União, de suas autarquias e fundações públicas, como as políticas públicas relacionadas à saúde, à educação, à moradia, à previdência social, dentre outras.

Uma atuação inadequada do exercício do cargo de advogado público federal pode, portanto, colocar em situação de vulnerabilidade o próprio Estado, razão pela qual se mostra pertinente a disposição do artigo 184 do $\mathrm{CPC} / 2015$, que prevê a responsabilidade do advogado público quando agir com dolo, má-fé ou fraude no exercício das funções. Ressalvadas essas hipóteses, estabelece o artigo 38, §§ 2o e 3으, da Lei № 13.327/2016, que não serão responsabilizados os ocupantes dos cargos das carreiras jurídicas federais ${ }^{10}$ quando no exercício de suas funções, exceto pelos respectivos órgãos correicionais ou disciplinares, competindo exclusivamente a esses órgãos a apuração de eventual falta disciplinar.

\footnotetext{
O artigo 2ํ, caput, da Lei no 9.469/97 (com redação dada pela Lei no 13.140/2015) estabelece que "o Procurador-Geral da União, o Procurador-Geral Federal, o Procurador-Geral do Banco Central do Brasil e os dirigentes das empresas públicas federais [...] poderão autorizar, diretamente ou mediante delegação, a realização de acordos para prevenir ou terminar, judicial ou extrajudicialmente, litígio que envolver valores inferiores aos fixados em regulamento".

8 Disponível em: https://www.agu.gov.br/page/content/detail/id_conteudo/200643. Acesso em: 10 jun. 2020.

9 De acordo com o artigo 109 da Constituição da República Federativa do Brasil, a referida Justiça Federal é responsável por julgar as causas de interesse da União, das entidades autárquicas ou empresas públicas federais, além daquelas que envolvam estados estrangeiros ou tratados internacionais, crimes políticos ou praticados contra bens, serviços ou interesses da União, e também dos crimes contra a organização do trabalho e a disputa sobre os direitos indígenas.

${ }^{10}$ A Lei no 13.327/2016 estabelece o seguinte: "Art. 27. Este Capítulo dispõe sobre [...] questões que envolvem os ocupantes dos cargos: I de Advogado da União; II - de Procurador da Fazenda Nacional; III - de Procurador Federal; IV - de Procurador do Banco Central do Brasil [...] Art. 38. São prerrogativas dos ocupantes dos cargos de que trata este Capítulo, sem prejuízo daquelas previstas em outras normas: [...] § 2o No exercício de suas funções, os ocupantes dos cargos de que trata este Capítulo não serão responsabilizados, exceto pelos respectivos órgãos correicionais ou disciplinares, ressalvadas as hipóteses de dolo ou de fraude. § 3 A apuração de falta disciplinar dos ocupantes dos cargos de que trata este Capítulo compete exclusivamente aos respectivos órgãos correicionais ou disciplinares".
} 
Não é raro, contrariamente à lei, que órgãos de controle, como tribunais de contas, iniciem procedimentos investigativos de atos praticados por advogados públicos, mesmo quando respaldados pelas chefias das procuradorias em que exercem suas funções, muitas vezes realizadas no contexto de uma política institucional de estímulo à autocomposição (reconhecimento jurídico do pedido, desistência e renúncia de recursos, transação, dentre outros). Essa situação não apenas viola a autonomia técnica desses profissionais, como frustra o modelo cooperativo adotado pelo CPC de 2015. Nesse sentido, Branco (2018, p. 473-474) reflete que

[...] a ausência de autonomia técnica [...] é [...] grave, tendo em vista a dificuldade que a deficiência cria para a inserção da Fazenda Pública no modelo cooperativo de processo. A vulnerabilidade perante órgãos de controle externos à Advocacia Pública a que se submete o advogado público que celebra um acordo em juízo é manifesta, o que desencoraja a postura conciliatória, mesmo quando há respaldo do órgão ao qual pertence.

O impacto da falta de prerrogativas da Advocacia Pública traduz-se no receio fundado dos membros da instituição de sofrer represálias de órgãos de controle quando da celebração de acordos (judiciais ou administrativos). É que a celebração de acordos envolve riscos ao profissional, que, muitas vezes, e por ausência de mínimas prerrogativas e de autonomia técnica, opta por simplesmente não os celebrar em nenhuma hipótese, adotando uma postura defensiva não condizente com modelo cooperativo e o dever de busca de solução consensual de conflitos. Nos casos em que uma solução consensual seria viável, tal postura (de recusa a celebração de acordos) por parte do advogado público resguarda-o, mas prejudica todos os envolvidos. A Fazenda Pública deixa de economizar, tendo em vista que o acordo significaria pagamento de valor menor que a integralidade da dívida. A parte deixa de ter seu direito imediatamente reconhecido e somente após longa jornada receberá o que lhe é devido [...].

A ausência de prerrogativas mínimas aos advogados públicos eleva o nível de exposição a risco institucional e financeiro do ente público, em especial quando se compara o arcabouço de garantias institucionais de que gozam outras funções essenciais à justiça (Defensoria Pública e Ministério Público) que demandam em grande escala em face do Poder Público.

Assim, a ausência de autonomia suficiente aos advogados da AGU não apenas os coloca em uma postura defensiva, como frustra a política estatal de solução consensual de conflitos, prejudicando a própria Fazenda Pública, as partes envolvidas e a própria sociedade.

Apesar de todos esses óbices, muitos membros da AGU conseguem viabilizar, de maneira criativa, alguns acordos fora do âmbito dos Juizados Especiais Federais, como em situações nas quais o processo está em fase de cumprimento de sentença e a proposição do acordo (em vez das medidas executivas impugnatórias) se mostra favorável para ambas as partes: à União porque são reduzidos os custos, e à parte exequente porque receberá mais rapidamente o seu crédito.

A propósito, quando tais medidas são adotadas de maneira institucional e são regulamentadas, com apoio dos órgãos superiores da AGU, os ganhos são de grande impacto. Exemplo disso é que, nos anos de 2017 e 2018, a celebração de alguns acordos em causas trabalhistas, pelo Departamento de Direitos Trabalhistas da Procuradoria-Geral da União, obteve a economia de mais de $\mathrm{R} \$ \mathbf{4}$ bilhões de reais dos cofres públicos e alcançou quase 11 mil trabalhadores. Os processos envolvidos no contexto dessa ação já haviam transitado em julgado e estavam, há anos, em fase de execução. A vultosa economia foi decorrência do deságio negociado nos acordos (valores que os reclamantes abrem mão em troca de um desfecho mais célere para o litígio) e dos juros que deixam de incidir sobre os valores devidos. Outro benefício é que os processos principais deixam de ser utilizados como fundamento para outras ações judiciais. Vale destacar, ainda, os seguintes trechos de reportagem sobre esse caso: ${ }^{11}$

"São diversas vantagens. Primeiro, gera uma economia [para os cofres públicos] em função do deságio nego-
ciado. Para os reclamantes, tem a facilidade de encerrar um litígio que, em alguns casos, vem durando até 30
anos. E para o Judiciário permite o encerramento de uma tramitação que poderia durar mais dez ou 15 anos",
pontua o diretor do Departamento de Direitos Trabalhistas, o advogado da União, Mario Guerreiro. "A dívida
vai se acumulando no decorrer de anos, com correção e juros. E o valor vai se tornando alto. Com as negocia-
ções, fazemos a análise da legalidade e da vantajosidade", acrescenta a advogada da União Lucia Helena Pigos-

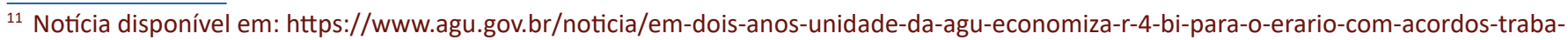
Ihistas--720017. Acesso em: 10 jun. 2020. 
si, que atua nas negociações dos acordos. Em média, os acordos são celebrados com 85\% de deságio para os cofres públicos. Um exemplo é conciliação que a Advocacia-Geral conseguiu celebrar para a Companhia Energética de Alagoas. A empresa era alvo na Justiça de uma ação movida pelo Sindicato dos Trabalhadores nas Indústrias Urbanas, que pleiteava o pagamento de $\mathrm{R} \$$ 1,7 bilhão para seus empregados. Após o acordo, o valor a ser pago foi reduzido para $\mathrm{R} \$ 350$ milhões. A solução do passivo trabalhista destravou a venda da empresa para a iniciativa privada. Além do Departamento de Direitos Trabalhistas, atuam nas negociações outras unidades da AGU, como o Departamento de Cálculos e Perícias da Procuradoria-Geral da União e procuradorias regionais e estaduais da União. Além dos acordos já celebrados em cinco dos dez maiores processos trabalhistas envolvendo a União, a AGU analisa e negocia atualmente acordos nos outros cinco. A lista não é divulgada para não prejudicar as tratativas.

Destaca-se, também, como apontado por Cambi e Vasconcelos (2015, p. 102-103), o pioneirismo da AGU quando instituiu as Câmaras de Conciliação e Arbitragem da Administração Federal (CCAF), com funcionamento desde 2007, cuja atribuição restou ampliada com a admissão de participação dos Estados, do Distrito Federal e dos municípios.

A referida CCAF é uma unidade vinculada à Consultoria-Geral da União e seus procedimentos conciliatórios tramitam, em regra, em Brasília, podendo, em raras hipóteses, haver descentralização para as unidades estaduais das Consultorias Jurídicas da União (CJU), mas sempre sob a supervisão do órgão central, sediado na referida capital. ${ }^{12}$

Frise-se, contudo, que mesmo a ampliação de atuação extrajudicial da CCAF encontra diversos óbices, seja pela falta de investimentos, seja pela ausência de autonomia dos membros da AGU, ou, mesmo, pela excessiva centralização dos órgãos localizados em Brasília.

Em verdade, ainda é muito presente a cultura de judicialização nas práticas envolvidas no âmbito da Administração Pública, como demonstrado em artigo baseado em pesquisa empírica, no qual Nunes (2018) observou cinco obstáculos práticos para a realização da conciliação nas ações em que é parte o Poder Público no âmbito da Justiça Federal, quais sejam: indisponibilidade do interesse público, ausência de respaldo institucional, "coragem" para fazer acordo, vanguarda da chefia e cultura do litígio.

De fato, como já mencionado anteriormente, embora deva ser superada a ideia de intransigibilidade do interesse público, para o fim de possibilitar o uso mais frequente e sistemático dos meios equivalentes de jurisdição, na prática os advogados que atuam nas unidades longínquas ao poder central da AGU não costumam possuir "margem" ou condição razoável (ou mesmo mínima) para instituir a melhor solução ou a gestão mais adequada do conflito por intermédio dos meios equivalentes.

É de se apontar, inclusive, que, em setembro de 2019, a maioria desses advogados públicos foi surpreendida, sem que tenha havido qualquer comunicação prévia ou oficial, por notícia divulgada pela mídia ${ }^{13}$ sobre o lançamento de uma plataforma digital da AGU que possibilita ao jurisdicionado fazer propostas de acordo em ações que litiga com a União.

A iniciativa foi da Procuradoria-Geral da União, órgão judicial superior, sediado em Brasília (DF), e, embora louvável, por objetivar criar as "Centrais de Negociação On-line" ${ }^{14}$, revela a carência de uma política coordenada e devidamente planejada com o envolvimento dos membros da AGU, para o fim de verdadeiramente efetivar e desenvolver uma estrutura adequada e permanente de utilização dos meios equivalentes de gestão de conflitos nas causas da União.

Desse modo, é imprescindível que se ultime uma regulamentação normativa adequada, capaz de viabilizar a efetivação dos meios equivalentes de jurisdição, no âmbito da Administração Pública, a ser realizada pela atuação da AGU. Com efeito, apenas com o oferecimento de condições estruturais e técnicas se mostrará viável o envolvimento da Administração Pública Federal no contexto da nova perspectiva do direito de acesso

\footnotetext{
12 Sobre o funcionamento da CCAF, verifique-se a "Cartilha CCAF". Disponível em: https://www.agu.gov.br/page/content/detail/id_ conteudo/217576. Acesso em: 25 maio 2019.

${ }_{13}^{13}$ Disponível em: https://extra.globo.com/noticias/economia/agu-lanca-plataforma-digital-para-receber-propostas-de-acordo-em-acoescontra-uniao-23955354.html. Acesso em: 10 jun. 2020.

${ }^{14}$ Disponível em: https://www.gov.br/pt-br/servicos/solicitar-negociacao-online-para-prevenir-ou-encerrar-litigios-judiciais-e-extrajudiciaiscontra-a-uniao?campaign=orgao. Acesso em: 10 jun. 2020.
} 
à justiça para a diminuição da litigiosidade vivenciada no país, com adequado tratamento aos conflitos, por meio da política estatal de consensualidade. Tal medida poderá promover, inclusive, uma melhoria da efetivação das políticas públicas relacionadas à saúde, à educação, à moradia, à previdência social, dentre outras.

\section{CONSIDERAÇÕES FINAIS}

No presente artigo partiu-se da premissa de que o Brasil vive uma crise de excesso de litigiosidade no âmbito do Poder Judiciário, bem como de que um dos instrumentos, eleitos como política nacional para a diminuição de litígios e seu adequado tratamento, é o incentivo aos meios equivalentes de jurisdição para a gestão de conflitos.

Apesar desse quadro, não se verifica, de uma forma geral, o oferecimento de condições estruturais e técnicas capazes de possibilitar a inserção integral da Administração Pública no contexto dessa nova perspectiva quanto à utilização das técnicas relativas aos meios equivalentes de jurisdição.

Destacou-se a existência de uma política pública oficial de solução de conflitos, que aponta para o "postulado da desjudicialização", enfatizando-se a sistemática do CPC/2015 e, em especial, de alguns de seus dispositivos, como o artigo 3 - (promoção da solução consensual dos conflitos), o artigo 60 (dever de cooperação), o artigo 190 (possibilidade de negociação processual) e o artigo 174 (câmaras de mediação e conciliação para solução consensual de conflitos no âmbito administrativo).

Apesar disso, diagnosticou-se que, em relação ao Poder Público, a partir do enfoque dado ao desempenho da AGU, a possibilidade de atuação, no âmbito dos meios equivalentes de jurisdição se dá, basicamente, nas Câmaras de Conciliação e Arbitragem da Administração Federal (CCAF), além de autorizações pontuais para celebração de acordos (limitadas por baixas alçadas e normalmente condicionadas à permissão de autoridades centrais e geograficamente distantes dos conflitos locais), ou, ainda, em raras hipóteses, condicionadas aos temas já definidos por jurisprudência sedimentada de cortes superiores ou sumuladas administrativamente, conforme a Lei Orgânica da AGU. Assim, apresentou-se extremamente limitada a atuação das Procuradorias da União nos Estados.

Também verificou-se que a ausência de autonomia (suficiente), relativamente aos membros da AGU, não apenas os coloca em uma postura receosa e defensiva, como frustra a política estatal de solução consensual de conflitos, prejudicando não apenas a própria Fazenda Pública, mas todas as partes envolvidas e a própria sociedade.

Concluiu-se, assim, que é imprescindível a existência de regulamentação normativa adequada para viabilizar a política de consensualidade no âmbito de atuação da AGU, traçando critérios objetivos e seguros para que seja realizada por todos os advogados públicos, lotados nas mais diversas procuradorias, envolvendo a Administração Pública Federal no contexto da nova perspectiva do direito de acesso à justiça.

Para tanto, é indispensável que o Advogado-Geral da União edite ato normativo ou proponha, ao presidente da República, a regulamentação necessária a uma plena atuação dos advogados da AGU, conforme previsão do artigo 4으, XVIII e XIX, da LC no 73/1993, estabelecendo-se, no mínimo, as hipóteses em que os órgãos de execução receberão delegação para celebrar acordos, bem como a sistemática baseada em valores escalonados de alçada.

Por fim, tendo em vista a relevância das questões envolvidas nas ações da União, de suas autarquias e fundações públicas, considera-se que um adequado tratamento, acerca das possibilidades de atuação dos advogados da AGU, que promova chances reais de consensualidade e de uso de meios equivalentes de jurisdição, poderão promover uma melhor efetivação das políticas públicas sociais, como as relacionadas à saúde, à educação, à moradia e à previdência social, dentre outras.

\section{REFERÊNCIAS}

ANDREWS, Neil. O moderno processo civil: formas judiciais e alternativas de resolução de conflitos na Inglaterra. Revisão da tradução Teresa Arruda Alvim Wambier. 2. ed. São Paulo: Revista dos Tribunais, 2012.

ASSIS, Araken de. Duração razoável do processo e reformas da lei processual civil. In: FUX, Luiz; NERY JR., Nelson; WAMBIER, Teresa Arruda Alvim. Processo e Constituição: estudos em homenagem ao professor José Carlos Barbosa Moreira. São Paulo: Revista dos Tribunais, 2006. 
BRANCO, Janaina Soares Noleto Castelo. Advocacia Pública no CPC/15 - Novo CPC: parte geral. Organização Juvêncio Vasconcelos Viana. Fortaleza: Expressão Gráfica e Editora, 2018.

BRASIL. Lei Complementar no 73, de 10 de fevereiro de 1993. Lei Orgânica da Advocacia-Geral da União.

BRASIL. Lei no 13.129, de 26 de maio de 2015a. Altera a Lei no 9.307, de 23 de setembro de 1996, e a Lei no 6.404, de 15 de dezembro de 1976.

BRASIL. Lei no 13.140, 26 de junho de 2015b. Dispõe sobre a mediação entre particulares como meio de solução de controvérsias e sobre a autocomposição de conflitos no âmbito da administração pública.

BRASIL. Lei no 13.327, de 29 de julho de 2016. Altera a remuneração de servidores públicos [...] e dá outras providências.

BRASIL. Lei $n$ o 9.307, de 23 de setembro de 1996. Dispõe sobre a arbitragem.

BRASIL. Lei no 9.469/97, de 10 de julho de 1997. Regulamenta o disposto no inciso VI do art. 4ㅇ da Lei Complementar no 73, de 10 de fevereiro de 1993 [...] e dá outras providências.

BRASIL. Lei no 10.259, de 12 de julho de 2001. Dispõe sobre a instituição dos Juizados Especiais Cíveis e Criminais no âmbito da Justiça Federal.

BRASIL. Lei no 13.105, de 16 de março de 2015c. Código de Processo Civil.

BRASIL. Resolução no 5, de 17 de dezembro de 2018, do Ministério da Educação. Institui as Diretrizes Curriculares Nacionais do Curso de Graduação em Direito.

CAMBI, Eduardo; VASCONCELOS, João Paulo A. Desjudicialização de políticas públicas e o Novo Código de Processo Civil contributo do Ministério Público e da Advocacia Pública à solução extrajudicial de conflitos. In: ARAÚJO, José Henrique Mota; CUNHA, Leonardo Carneiro (org.). Advocacia pública. Salvador: Juspodivm, 2015. (Coleção Repercussão do novo CPC, vol. 3).

CARMONA, Carlos Alberto. Arbitragem e processo: um comentário à Lei no 9.307/96. 2. ed. São Paulo: Atlas, 1998.

CNJ. Conselho Nacional de Justiça. Justiça em números de 2019. Disponível em: https://www.cnj.jus.br/pesquisas-judiciarias/ justica-em-numeros/. Acesso em: 10 jun. 2020.

CNJ. Conselho Nacional de Justiça. Resolução no 125, de 29 de novembro de 2010.

FACCI, Lucio Picanço. A utilização de meios consensuais de resolução de conflitos pela Administração Pública e o Novo Código de Processo Civil. In: ARAÚJO, José Henrique Mota; CUNHA, Leonardo Carneiro (org.). Advocacia pública. Salvador: Juspodivm, 2015. (Coleção Repercussão do novo CPC, vol. 3).

FALCÃO, Joaquim; CERDEIRA, Pablo Camargo; ARGUELHES, Diego Werneck. I Relatório Supremo em números: o múltiplo Supremo. Rio de Janeiro: FGV, 2011.

FISS, Owen. Um novo Processo Civil: estudos norte-americanos sobre Jurisdição, Constituição e sociedade. Coordenação da tradução Carlos Alberto Salles. São Paulo: Editora Revista dos Tribunais, 2004.

FRANCO, Marcelo Veiga. Câmaras de mediação e conciliação na Fazenda Pública: o artigo 174 do Novo Código de Processo Civil como contribuição para o acesso à justiça "desjudicializado". In: ARAÚJO, José Henrique Mota; CUNHA, Leonardo Carneiro (org.). Advocacia pública. Salvador: Juspodivm, 2015. (Coleção Repercussão do novo CPC, vol. 3).

GRIEBLER, J.; SERRER, F. Sistema multiportas de justiça e a atuação do projeto de extensão conflitos sociais e direitos humanos. Revista Direito em Debate, v. 29, n. 53, p. 168-181, 26 maio 2020.

JORGE NETO, Nagibe de Melo. Abrindo a caixa preta: por que a Justiça não funciona no Brasil? 1. ed. Salvador: Editora Juspodvm, 2016.

MADUREIRA, Claudio. Advocacia pública. 2. ed. Belo Horizonte: Fórum, 2016.

MANCUSO, Rodolfo de Camargo. Acesso à Justiça: condicionantes legítimas e ilegítimas. 2. ed. São Paulo: Revista dos Tribunais, 2015.

MAUS, Ingeborg. O Judiciário como superego da sociedade: o papel da atividade jurisprudencial na "Sociedade Órfã". Revista Novos Estudos, São Paulo, n. 58, p. 183-202, 2000.

NUNES, Thais Borzino Cordeiro. A aplicação dos meios consensuais de solução de conflito em ações envolvendo a Fazenda Pública no âmbito da justiça administrativa. Revista CEJ, Brasília, ano XXII, n. 74, p. 46-55, jan./abr. 2018.

REIS, B.; BORGES, G.; SILVA NETO, N. Mediação de conflitos e compliance trabalhista: medidas para prevenção, gestão e resolução consensual de conflitos. Revista Direito em Debate, v. 29, n. 53, p. 40-54, 26 maio 2020.

THEODORO JÚNIOR, Humberto et al. Novo CPC - fundamentos e sistematização. Rio de Janeiro: Forense, 2015. 